\title{
Chronic Androgen Treatment Increases Action Potential Duration in the Electric Organ of Sternopygus
}

\author{
Alice Mills and Harold H. Zakon \\ Department of Zoology, University of Texas at Austin, Austin, Texas 78712
}

The quasi-sinusoidal electric organ discharge (EOD) of the weakly electric fish Sternopygus is involved in communication and orientation. Each monophasic pulse of the lowintensity EOD is a compound action potential (AP) from the simultaneously firing electrocytes of the electric organ. EOD frequency is lower and EOD pulse duration longer in sexually mature males than in sexually mature females; exogenous androgen lowers EOD frequency and increases EOD pulse duration. In order to determine the contribution of single electrocyte spikes to the entire EOD pulse, APs were induced by intracellular current injection in single electrocytes of isolated pieces of electric organ. Each AP looks very similar to the externally recorded EOD pulses, and AP duration (APD) is significantly correlated with EOD pulse duration $(r=0.48 ; p<0.0005)$. The APD is slightly longer when compared to the EOD pulse duration, but this difference is likely due to the stimulation paradigm. Fish treated with dihydrotestosterone showed a decrease in EOD frequency, increase in EOD pulse duration, and corresponding increase in APD; control fish showed random, insignificant changes in EOD wave form and APD. Evidence presented here shows that changes in the passive membrane properties are unlikely to be responsible for the APD increase. The possibility is discussed that androgens act directly upon the electric organ, ultimately altering the ionic currents that produce the AP.

Sex differences in behavior are common among vertebrates, especially in courtship and reproduction (fish: Bass, 1986b; amphibians: Kelley, 1986; birds: Arnold et al., 1986; mammals: Sengelaub, 1989). Endogenous sex steroids are responsible for many of these sex differences. Studies of the effects of steroid hormones on the neural circuitry underlying sex-specific behaviors can be difficult to interpret because of their inherent complexity. For instance, many CNS nuclei and peripheral effectors may control or influence a behavior, the cells within a particular nucleus are not necessarily homogeneous in function or response to steroid, and it is difficult to determine whether hormone effects are pre- or postsynaptic. Therefore, it is not

\footnotetext{
Received Dec. 3, 1990; revised Feb. 26, 1991; accepted Feb. 27, 1991.

This work was supported by NIII Grants NS25513-02 and NS01278-03, and ONR 11415BS to H.H.Z. We wish to thank Drs. W. Thompson, J. Larimer, and M. Winkler for helpful comments on the manuscript and Drs. W. Thompson, L. Fleishman, and G. Pollak and C. Resler for technical advice and loan of equipment. We extend special thanks to Emily Guzman and Susan Gustavson for fish care and to Guillermo Feo and Dr. D. Taphorn for assistance in fish collection.

Correspondence should be addressed to Dr. Alice Mills, Department of Psychology/Program in Neural Science, Indiana University, Bloomington, IN 47405. Copyright (C) 1991 Society for Neuroscience $0270-6474 / 91 / 112349-13 \$ 03.00 / 0$
}

easy to discern the contribution of steroid effects upon a particular region to the control of an entire behavior.

Results from studies of chronic electrophysiological effects of steroid hormones include changes in refractory period and cell responsiveness in different neural regions (Kendrick and Drewett, 1979; Chan et al., 1985). How these steroid effects change the associated behavior is unclear. The androgen-sensitive electrocommunication system of the weakly electric fish is an attractive model for studying long-term effects of steroids on excitable cells, because the association between steroid effects and behavior is more apparent.

Weakly electric fish continually produce an electric organ discharge (EOD), via a relatively simple neural circuit; the EOD is both a behavioral event and a discrete electrophysiological phenomenon (Bass, 1986b). The EOD of weakly electric fish is used in communication (Hopkins, 1972, 1974, 1980; Gottschalk, 1981; Hopkins and Bass, 1981; Westby and Kirschbaum, 1981, 1982; Hagedorn and Heiligenberg, 1985; Moller and Serrier, 1986) and electrolocation (Lissmann, 1958; Lissmann and Machin, 1958; Bullock, 1982). The EOD of many South American gymnotiform species is nearly sinusoidal in wave form, consisting of very regularly spaced monophasic pulses; such fish are called "wave" fish, because the EOD oscillogram is wavelike in appearance. Other South American gymnotiforms and the African mormyrids produce an EOD in which the pulses are relatively brief in duration, often multiphasic, and occur with an irregular rhythm; these fish are called "pulse" fish because the EOD wave form is pulselike (Bennett, 1971). In both pulse and wave fish, each EOD pulse is a compound action potential (AP) formed by the summed APs in the individual cells of the electric organ, the electrocytes (Bennett, 1971). The frequency of the EOD pulses in wave fish is determined by the medullary pacemaker nucleus (PMN) in the brain (Bennett et al., 1967; Ellis and Szabo, 1980); the PMN activates the electromotor neurons, which drive the muscle-derived electrocytes (Bennett, 1971; Baillet-Derbin, 1978) of the electric organ, located in the posterior portion and tail of the fish. (There also exist wave-fish species, the Apteronotids, in which the electric organ is neurally derived; Bennett, 1971.)

Sex differences in the EOD have been described in both pulse and wave fish. In pulse species, the wave form of the pulse varies between reproductively mature fish, typically being of longer duration in males (Bass and Hopkins, 1983, 1985; Hagedorn and Carr, 1985; Landsman and Moller, 1988; Freedman et al., 1989). In wave species, on the other hand, mature males and females discharge at different frequencies (Hopkins, 1974; Meyer, 1983). These sex differences can be mimicked in the laboratory by androgen treatment. The EOD pulse of female or juvenile pulse fish is broadened by androgen treatment, and the 
EOD frequency of the wave fish Sternopygus is lowered. Thus, it was believed that the target of androgen is the electric organ in pulse fish and the PMN in wave fish. However, we have previously shown that the androgen dihydrotestosterone (DHT) not only lowers EOD frequency, but also increases the EOD pulse duration of Sternopygus (Mills and Zakon, 1987). This is not surprising, in that the duration of each pulse must be longer when the EOD frequency is lower, if a sinusoidal discharge is to be maintained. It was not clear from that study, which only recorded the EOD, whether the wave form of the individual electrocyte APs was altered by the hormone, or whether the timing of firing was changed such that electrocyte spikes were summed over a longer period of time, resulting in a broader single EOD pulse.

In this study, we wished to determine the relationship between electrocyte APs and the entire EOD pulse, and whether androgen treatment could increase the duration of single APs. Electrocytes were stimulated by intracellular current injection; the resulting APs were described and quantified and were compared to similar parameters measured from the EOD pulses. A group of these fish was then treated with DHT, to see if AP duration (APD) is increased by androgen treatment as is the EOD pulse.

\section{Materials and Methods}

Experimental subjects. Fifty-two Sternopygus macrurus were used in this study, selected to represent as much as possible of the entire range of EOD frequencies for this species, $40-180 \mathrm{~Hz}$ at $25^{\circ} \mathrm{C}$. The fish were caught in Venezuela, in lakes or ditches, near Ciudad Bolivar or in Estado Apure. The fish were kept in the lab in large group tanks. The tanks were maintained at approximately $25^{\circ} \mathrm{C}$ on a 12 -hr: 12 -hr light/ dark cycle, and the fish were fed earthworms two or three times weekly. Fish used in the hormone implant study were transferred to 15-gallon aerated aquaria, with two fish per tank, separated by a divider. All fish were allowed to equilibrate to these conditions for at least 3 weeks prior to participation in experiments. Fish were less than $30 \mathrm{~cm}$ in length from snout to tail tip (range, $14-28 \mathrm{~cm}$; mean, $21 \pm 4 \mathrm{~cm}$, SD); thus they were juvenile (Hopkins, 1972, 1974).

Intracellular data collection. Prior to baseline recording, each fish was removed from its aquarium and allowed to cool to room temperature $\left(20.2-23.5^{\circ} \mathrm{C}\right.$; mean, $\left.22.4 \pm 0.7^{\circ} \mathrm{C}, \mathrm{SD}\right)$ in a small amount of tank water in a plastic bucket; this allowed for direct comparison of APs recorded at room temperature with the EOD pulses, because the intracellular recording chamber was not temperature controlled (the EOD and APs are sensitive to temperature change; Keynes and MartinsFerreira, 1953; Lissmann, 1958; Enger and Szabo, 1968). The EOD was recorded differentially near the fish's tail, through a Grass P-15 amplifier ( $3 \mathrm{~Hz}$ to $10 \mathrm{kHz}$ band pass), and the frequency was measured by a Fluke digital frequency counter. EOD traces were stored on a Standard 286 computer (IBM-AT clone), using the neurophysiological acquisition and analysis program SPIKE (Neurologics), which received the signal through a World Precision Instruments (WPI) Universal Signal Manifold. Sampling rate for collection of traces was $20 \mathrm{kHz}$.

A 1-1.5-cm piece of tail was cut from the fish with scissors and placed in room-temperature Hickman's physiological saline with $3 \mathrm{~mm}$ glucose in a Sylgard-coated (Dow Corning) recording dish. The skin was peeled from the tail with coarse forceps, thereby exposing the electrocytes.

Electrodes were pulled on a Flaming Brown P-80/PC (Sutter Instrument Co.) from borosilicate-glass micropipettes (A-M Systems or Dagan). Electrodes were filled with $3 \mathrm{M} \mathrm{KCl}$ and connected to either a WPI $707 \mathrm{~A}$ or Intra- 767 intracellular amplifier. Electrode resistance during recording averaged $15 \pm 12 \mathrm{M} \Omega(\mathrm{SD})$. Two electrodes were put into each cell. Current was passed in "breakaway" mode into the cell, through the more posterior electrode. The posterior electrode was chosen for current passing to minimize the current required for spiking, because only the posterior end of the cell is electrically excitable (Bennett, 1971). The more anterior electrode in the cell recorded cell response relative to ground. Two electrodes were needed to produce and record APs because the large cells $(0.4-4 \mathrm{~mm}$ long $\times 50-600 \mu \mathrm{m}$ diameter; Schwartz et al., 1975; A. Mills, H. H. Zakon, and $\Lambda$. H. Bass, unpublished observations) required an amount of current that saturated the amplifiers.

Current was provided by a WPI $302 \mathrm{~T}$ stimulator with isolation unit. Current was injected as a square pulse of short (0.1-6.2 msec) or long $(16-20 \mathrm{msec})$ duration, at a frequency of $1-3 \mathrm{~Hz}$. Stimulus intensity was gradually increased from 0 until spike threshold was reached, and was maintained just above this level. For short-duration stimuli, if the stimulus intensity was at its maximum and there still was no AP, the stimulus duration was gradually increased until the cell fired. AP and stimulus traces were stored on the computer in SPIKE, as were the EODs. Current ranged in magnitude from 46 to $588 \mathrm{nA}$. The preamplifier to the computer became saturated at $588 \mathrm{nA}$, so current was in reality often larger. Presumably, more current was required when the electrodes were far from the spiking membrane. As many cells as could give "good" APs (of normal shape, $20 \mathrm{mV}$ or more amplitude, and $-50 \mathrm{mV}$ or more resting potential) were recorded. (Only 17 out of 235 cells had amplitudes less than $30 \mathrm{mV}$, and only 20 out of 235 cells had resting membrane potentials more depolarized than $-50 \mathrm{mV}$.) The tissue was viable for more than $7 \mathrm{hr}$.

DHT treatment. Twenty-two fish with frequencies above $92 \mathrm{~Hz}$ at room temperature were used, because the decrease in EOD frequency in response to DHT is larger in higher-frequency fish (Zakon and Meyer, 1983). The fish were randomly assigned to either DHT $(N=14)$ or control $(N=8)$ treatment. Pretreatment recordings were made in vitro from electrocytes in a small piece of electric organ as described previously; each fish was then implanted intraperitoneally with either a DHTfilled (5- $\alpha$-dihydrotestosterone, Sigma) or an empty Silastic capsule (Dow Corning) of $0.5-1.0 \mathrm{~cm}$ in length. Treatment with DHT in this manner has been shown to produce physiological concentrations $(1-10 \mathrm{ng} / \mathrm{ml})$ of that steroid in the blood (Keller et al., 1986). The fish were lightly anesthetized with tricaine methane sulfonate (MS-222; Sigma) for this surgical procedure, and the aquaria were treated with Stress Coat (Aquarium Pharmaceuticals, Inc.) to stimulate replacement of the slime coat, which was disturbed during handling.

The fish were revived, returned to their tanks, and checked every few days with the frequency counter to ensure that the DHT-treated fish were responding to the implants by lowering of EOD frequency. If there was no change in frequency after 1 week, or if the DHT capsule fell out, the fish was reimplanted. Some control fish were also reimplanted with empty capsules to control for any effects of multiple surgeries. After 4 weeks, or when EOD frequency had dropped by at least $19 \mathrm{~Hz}$ in the DHT-treated fish, another segment of tail was removed and recorded from as before. The cut was made at least $1 \mathrm{~cm}$ anterior to the previous cut, which could still be clearly seen even though the tip of the tail had almost completely regenerated; this was to eliminate regenerating electrocytes from the recordings.

Data analysis. Resting membrane potential $\left(V_{m}\right)$ was read from the oscilloscope screen upon initial electrode penetration and again after $V_{m}$ stabilized and electrophysiological data were taken. This was necessary because the first electrode often came out of the cell when the second electrode entered; thus many cells were repeatedly impaled, in order to get both electrodes inside simultaneously. In cases in which this initial $V_{m}$ was recorded, it was noted that, upon stable penetration by two electrodes, the cell was slightly depolarized from the initial value. Generally, over the course of a few (less than 5) $\mathrm{min}$, the $V_{m}$ would gradually repolarize, but not to the initial $V_{m}$.

Stored traces were displayed on the computer. Cursors were moved to desired points on the traces, to measure duration and amplitude. EOD pulse duration was measured from beginning to end as described in the previous study (Mills and Zakon, 1987). In addition, the fall time of the pulse was measured, the rise time was calculated as total duration minus fall time. EOD frequency was also calculated as the inverse of the EOD period measured in SPIKE. Calculated versus measured EOD frequencies were in most cases identical; they never differed by more than $2 \mathrm{~Hz}$. Thus, measurement error in this study is not attributable to SPIKE, the sampling frequency, or the monitor screen resolution, but rather to consequences of electrode penetration of cells. EOD duty cycle was calculated as pulse duration/EOD period. EOD intensity was not quantified.

There was often some variability in appearance of long APs: the amplitude or duration could change slightly over the course of a few seconds before stabilizing. In such records, the traces with stable spikes of the highest amplitude and clearest start and end points were preferentially measured for a given cell. APs elicited by $16-20-\mathrm{msec}$ stimulus pulses ("long" spikes) were measured from the initial deflection away 

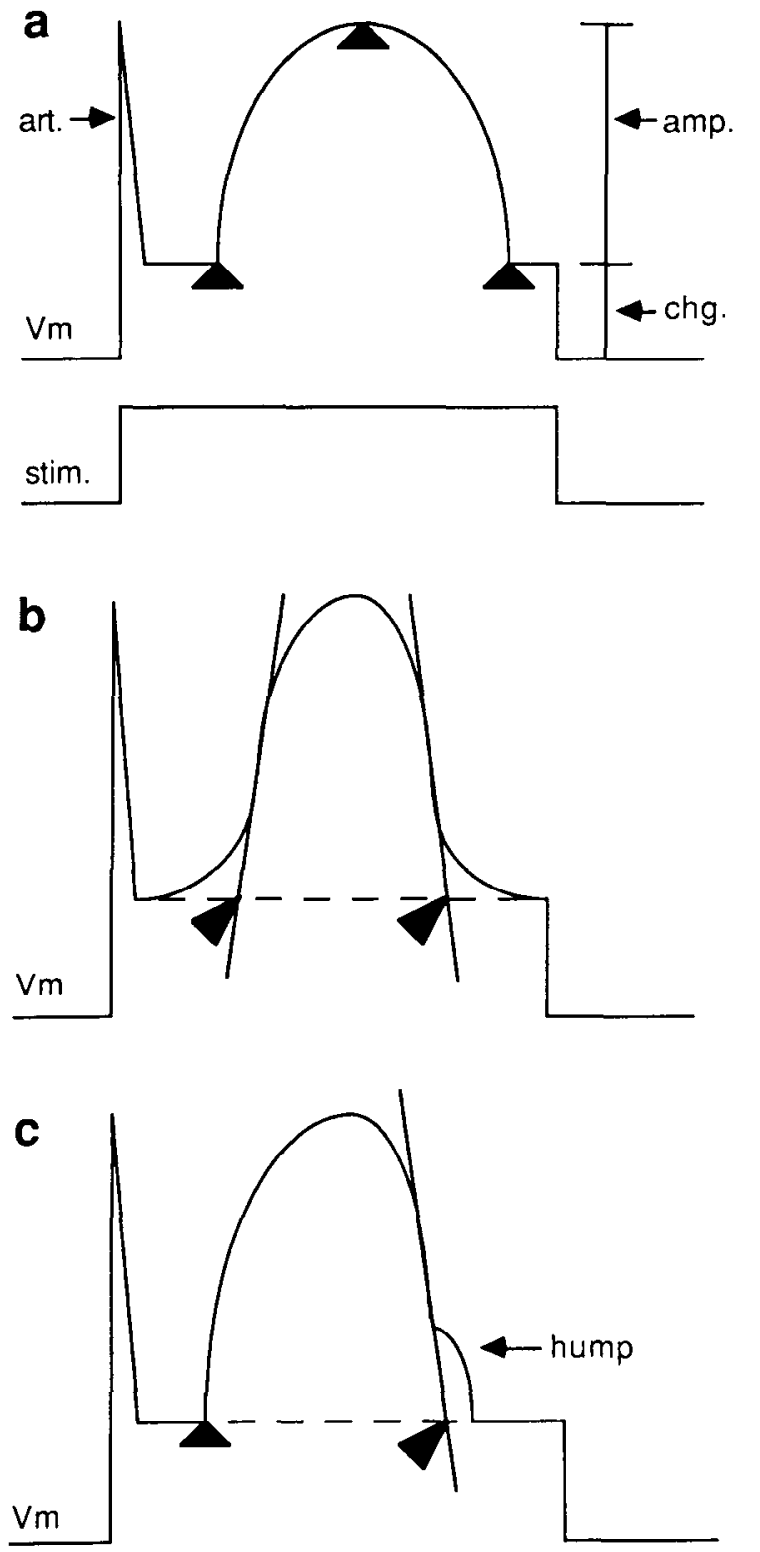

Figure 1. Three generalized spike shapes are shown in $a-c$. Resting membrane potential is indicated as $V_{m}$. Spike beginning, end, and peak are indicated with triangles; spike duration is the distance between the two lower triangles. a, The stimulus pulse is shown (stim.), as well as the capacitative artifact (art.) and charging component upon which the spike is superimposed ( $c h g$.). Spike amplitude ( $a m p$.) is defined as the distance between the peak of the spike and the top of the charging component (see Materials and Methods for explanation). $b$, Spikes that had indistinct beginning and end points were measured at the intersection of the predominant slopes of the rising and falling phase, with the top of the charging component (broken line). $c$, Humps were eliminated from the duration measurcment by extending a line from the predominant slope of the falling phase of the spike and measuring to the point at which the line intersected the top of the charging component.

from the baseline formed by the cell-charging potential, to the point at which the trace rejoined this baseline, judged by eye (the AP began and ended during the stimulus pulse, and thus the AP was superimposed on the charging pulse; Fig. $1 a$ ). In cases in which the AP was somewhat obscured by stimulus artifact or capacitative interaction between the electrodes, a subthreshold trace that did not contain an AP was subtracted in SPIKF from the corresponding trace containing an AP; this produced an uncontaminated spike trace. Some long APs had an indistinct beginning or end. In those few cases, a straight edge was used

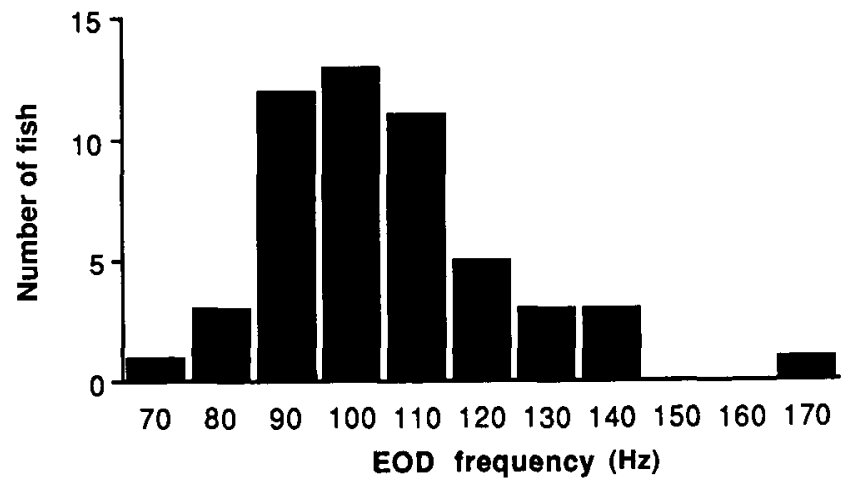

Figure 2. EOD frequency distribution of the 52 fish used in the AP characterization portion of this study. Frequencies are separated into $10-\mathrm{Hz}$ bins.

to extend a line from the predominant falling or rising slope to the baseline of the AP; APD was then the time difference between the points at which the line or lines met baseline (Fig. 1b). The few APs that had "humps" in the falling phase were similarly measured (Fig. 1c). (Humps appeared on APs in both treatment groups.) The duration of the falling phase was measured as the time from the peak of the spike to the end; rise time was calculated as total APD minus fall time. These measurement adjustments were made in a minority of the APs.

AP amplitude was measured as the difference between the peak of the spike and the top of baseline formed by the cell-charging potential (Fig. 1a). Resting $V_{m}$ baseline was not used because the magnitude of the cell-charging potential was often exaggerated (sometimes the currentpassing electrode was far from the active region of the electrocyte membrane; thus a larger amount of current was needed to charge the cell to threshold). For cases in which this charging potential was not large and only a small amount of current was required to bring the cell to threshold, AP amplitude was also measured from the resting $V_{m}$ baseline.

The onset of APs induced by short-duration stimulus pulses ("short" spikes) was almost always obscured by stimulus artifact. The duration of these APs was thus measured only from the peak of the AP, judged by eye, to the resting potential baseline. EOD pulse and long AP fall times were compared to this short APD.

The electrophysiological parameters reported in Results are the average of four successively acquired traces. The EOD measurements are the average of four neighboring EOD pulses. The average AP parameters from each electrocyte in a given fish were then averaged together to produce a mean value, for comparison with the fish's EOD pulse. For the general characterization of APs and their relationship to the EOD, only data from untreated fish, or from fish in the DHT study but prior to treatment, were used.

Statistical analysis. Average values are reported as the mean \pm standard deviation (SD) or, where noted, standard error. Correlational data were analyzed for significance using Fisher $Z$ values. The Wilcoxon signed-rank test was used to analyze all paired data in the AP characterization study. Pre- and posttreatment differences in the DHT study were analyzed for significance using the Wilcoxon signed-rank test, for comparison within a treatment group, and the Mann-Whitney $U$ test, for comparison between treatment groups. Significance levels are all twotailed except where noted, and $p$ values are reported as appropriate in Results. Any $p \geq 0.05$ was not considered significant.

\section{Results}

\section{EOD parameters}

The span of EOD frequencies in this study was 76-171 Hz (Fig. 2); EOD pulse durations ranged from 4.33 to $9.12 \mathrm{msec}$. Both ranges overlap those in our earlier study (Mills and Zakon, 1987), though the earlier measurements were at a higher temperature $\left(25^{\circ} \mathrm{C}\right)$ than in the current study (room temperature). The correlation between EOD pulse duration and EOD frequency was high $(r=-0.83 ; p<0.00005)$ and in good agreement with the previous study. Again, fish with low EOD frequencies had broad pulse durations, and fish with high EOD 
a low frequency fish

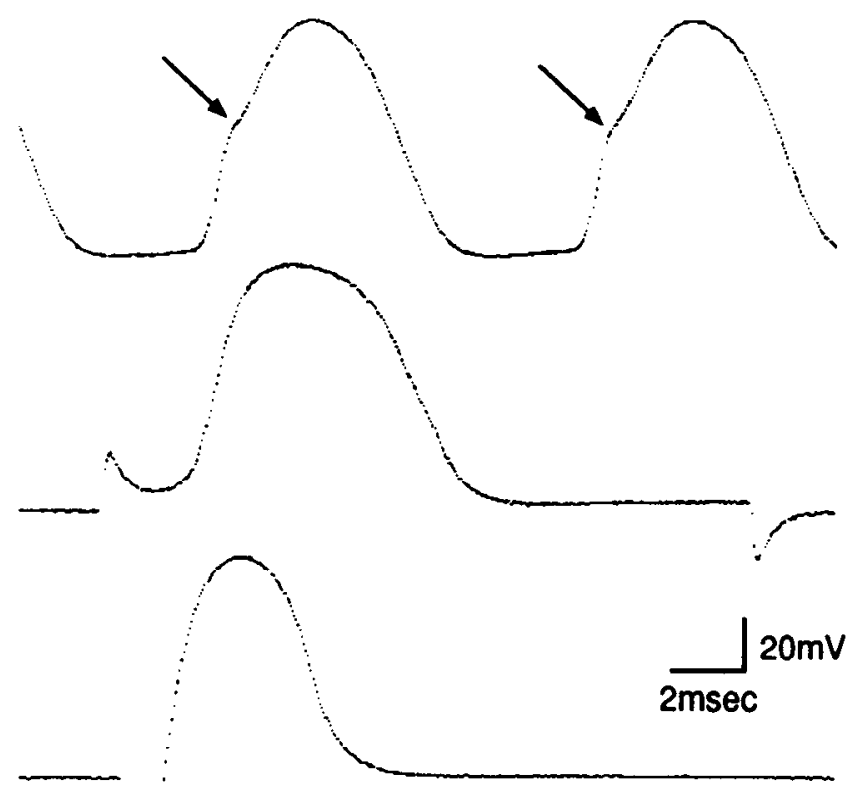

b

high frequency fish

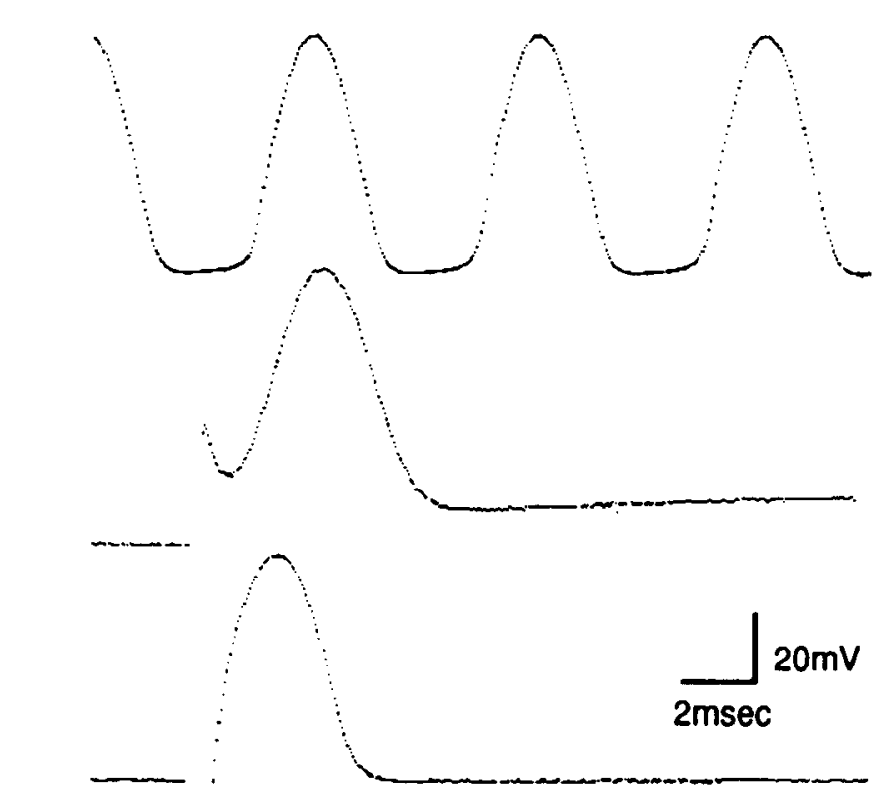

Figure 3. EOD pulse (top trace), long spike (middle trace), and short spike (bottom trace), from a fish of low (a) and high (b) EOD frequency. Arrows denote inflections. Scale bars represent time in all three traces, and amplitude in only the long-and short-spike traces.

frequencies had short pulse durations (Fig. 3, top traces). Duty cycle ranged from $48 \%$ to $82 \%$ (mean, $70 \pm 5 \%$ ) and was also correlated with EOD frequency $(r=0.32 ; p<0.02)$, but was not correlated with EOD pulse duration.

As described qualitatively in the earlier study, the EOD pulse rises to peak faster than it falls back to baseline. Rise time ranged from 1.78 to $4.06 \mathrm{msec}$ and averaged $39 \%$ of pulse duration; fall time ranged from 2.35 to $5.26 \mathrm{msec}$ and averaged $61 \%$ of pulse duration. This ratio was constant across EOD pulse durations; thus longer-duration pulses have both longer rise times $(r=0.92 ; p<0.00005)$ and longer fall times $(r=0.94 ; p<$ 0.00005 ) than shorter-duration pulses. There was no significant tendency for longer pulses to have a higher or lower percent rise or fall (Fig. 4a). The EOD pulse in lower-frequency fish occasionally had a slight inflection in the rising phase (Fig. $3 a$ ), as seen in the prior study.

\section{Intracellular recordings}

Spikes were recorded from a total of 235 cells; the number of cells recorded per fish varied from 1 to 16 , with a mean of four or five cells per fish. Initial $V_{m}$ of each fish was $-76 \pm 8 \mathrm{mV}$ (range, -52 to $-117 \mathrm{mV}$ ). Final $V_{m}$ (measured a few minutes after the termination of each cell's recording session) ranged from -30 to $-97 \mathrm{mV}$ in individual cells (fewer than $10 \%$ of the cells had a $V_{m}$ more depolarized than $-50 \mathrm{mV}$; because removing the data of such cells from the analysis had a negligible effect upon the results, the data were included). The average final $V_{m}$ for each fish ranged from -44 to $-85 \mathrm{mV}$ (mean, 69 $\pm 14 \mathrm{mV}$ ). This is in agreement with the $V_{m}$ reported for Sternopygus by Bennett (1961). Initial $V_{m}$ was almost always greater than final $V_{m}$, by an average of $10 \pm 9 \mathrm{mV}(p<0.005)$. Thus, the cells generally stabilized $10 \mathrm{mV}$ depolarized from initial resting $V_{m}$, indicating slight damage by electrodes.

The $V_{m}$ measured at the end of a cell's recording session at the injection electrode, which was placed more posteriorly and thus closer to the active membrane than the recording electrode, was generally more negative than the $V_{m}$ at the recording electrode in the present study and in Bennett's study (1961). The mean difference between the $V_{m}$ at the different electrodes was $4 \pm 6 \mathrm{mV}(p<0.001)$. Bennett (1971) reported a $3-\mathrm{mV}$ difference in one Sternopygus electrocyte in situ, also with the more posterior electrode registering a lower $V_{m}$ than the more anterior electrode. Thus, $V_{m}$ varies slightly with electrode placement.

Long spikes. The amplitude of long spikes in all fish was 24$98 \mathrm{mV}$ (mean, $53 \pm 18 \mathrm{mV}$ ), as measured from the top of the charging component to the peak of the spike. The potential reached by the peak of the AP averaged $-11 \pm 12 \mathrm{mV}$; thus, most APs did not overshoot $0 \mathrm{mV}$. In 26 of the lowest-threshold cells (threshold at 15-35 $\mathrm{mV}$ depolarization from $V_{m}$ ) with highamplitude spikes, amplitude was measured from resting potential to the peak of the spike, as well. Half of these amplitudes were below $0 \mathrm{mV}$, and half were up to about $+35 \mathrm{mV}$ above. Amplitude was correlated with the magnitude of $V_{m}(r=0.43$; $p<0.001)$ and with long APD $(r=0.30 ; p<0.05)$, and $V_{m}$ was correlated with long APD $(r=0.25 ; p<0.05)$; these correlations indicate that cells with more depolarized resting potentials will have lower-amplitude and shorter-duration APs. This is one probable source of variation in spike measurements.

APs produced with long-duration stimulus pulses, which bypassed the electromotor synapse, were similar in appearance to EOD pulses, though not identical (Fig. 3, middle traces). APD was 4.4-10.6 msec and was significantly correlated with EOD frequency $(r=-0.47 ; p<0.0005)$ and EOD pulse duration (Fig. $5 ; r=0.48 ; p<0.0005$ ). APs were on average $0.75 \pm 1.21$ msec greater than the duration of the EOD pulse $(p<0.005)$. Rising inflections were never seen in electrocyte APs induced by direct stimulation. Often, the peak of the AP appeared to be broader or rounder than that of the EOD pulse.

The mean rise time of long APs was 1.86-3.56 msec, on average $36 \%$ of APD. Mean fall time was $3.06-6.96 \mathrm{msec}$, on 


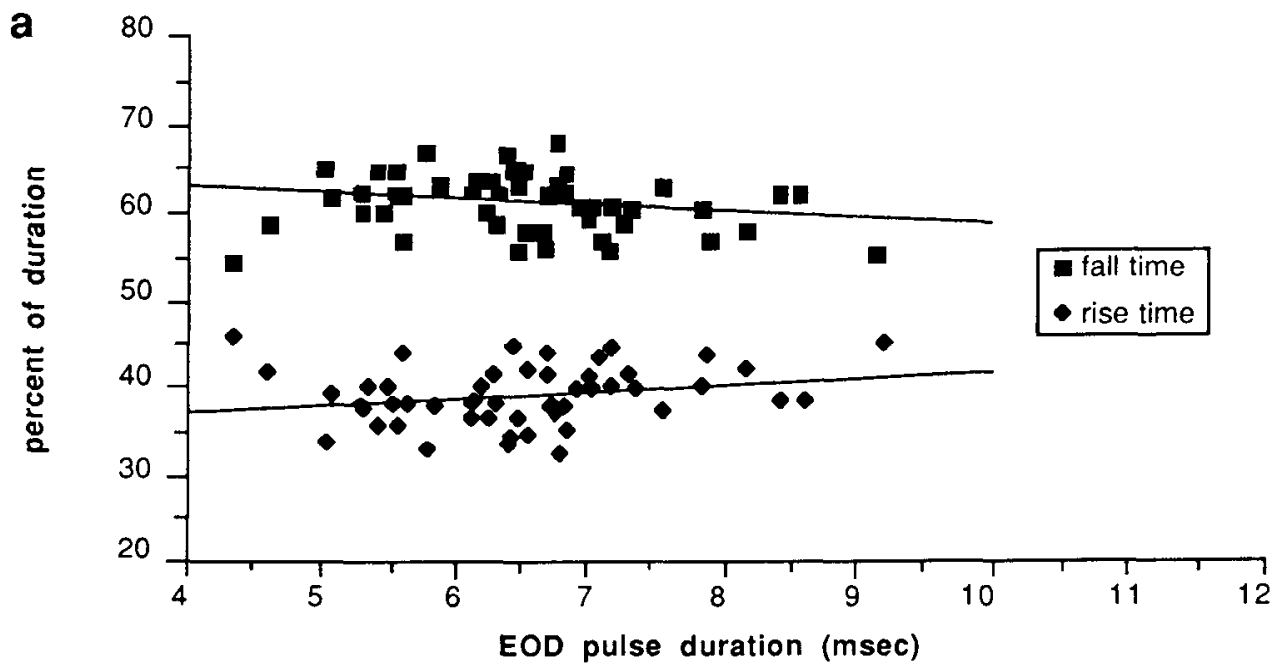

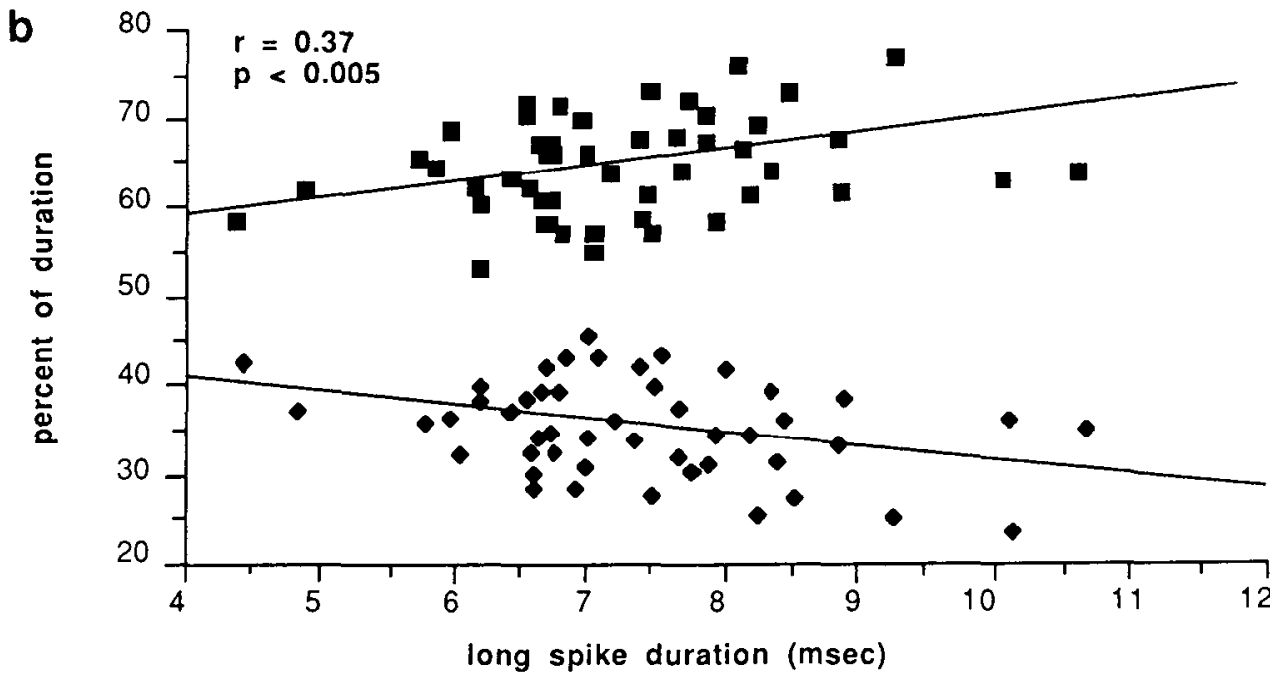

Figure 4. a, EOD rise and fall times, as percent of total EOD pulse duration, are constant across all EOD pulse durations. Average percent rise, 39\%; average percent fall, $61 \%$. $b$, Long-spike rise and fall times, as percent of total spike duration, are significantly correlated with spike duration. Average percent rise, $36 \%$; average percent fall, $64 \%$. Regression lines are shown. average $64 \%$ of APD. Rise and fall times of long APs were significantly correlated with long APD (rise: $r=0.60, p<$ 0.00005; fall: $r=0.93, p<0.00005$ ); thus, longer APs both rose and fell more slowly than shorter APs. There was also a tendency for longer APs to have a lower percent rise time and higher percent fall time than shorter APs $(r=0.36 ; p<0.005)$, indicating that fall time increases more than rise time in longerduration spikes (Fig. 4b).

AP rise and fall times were also significantly correlated with EOD pulse rise and fall times (long AP fall vs. EOD fall: $r=$ $0.24, p<0.05$; long AP rise vs. EOD rise: $r=0.64, p<0.00005$ ). AP fall time was generally longer than EOD pulse fall time (Fig. 6). The difference ranged from $1.53 \mathrm{msec}$ shorter to $2.77 \mathrm{msec}$ longer than EOD fall time (mean difference, $0.73 \pm 0.99 \mathrm{msec}$ longer than EOD fall time; $p<0.005$ ). AP rise time was not statistically different from EOD rise time, hence the much higher correlation between the rise times of AP and EOD pulses compared to the fall-time correlations. This indicates that the greater duration of the falling phase of the long AP is responsible for the greater duration of the entire AP relative to the EOD pulses, and for the difference in percent rise and fall time of the long AP compared to the percent rise and fall time of the EOD pulses.

In about $30 \%$ of the long APs, a slight to marked "hump" appeared in the falling phase. (As mentioned in Materials and Methods, the hump duration was eliminated from the APD measurements.) The humps represent very labile components of membrane activity, in that over the course of a few tens of seconds, a hump could appear or disappear, or change in magnitude. For a given cell with a variable hump, those APs in which the hump was smaller or absent altogether were preferentially measured over those with a (larger) hump. Very slightly altering the stimulus intensity could change the appearance of the hump. A higher stimulus intensity resulted in elimination of the hump and produced a second, albeit lower amplitude and shorter duration, spike. The secondary AP was smaller probably because it occurred during the relative refractory period of the electrocyte; in a related species, this period was reported to be $15 \mathrm{msec}$ (Altamirano et al., 1953). Thus, it appears that the hump merely represents a slowing of AP repolarization, due to a second AP "trying" to fire during the stimulus pulse. 


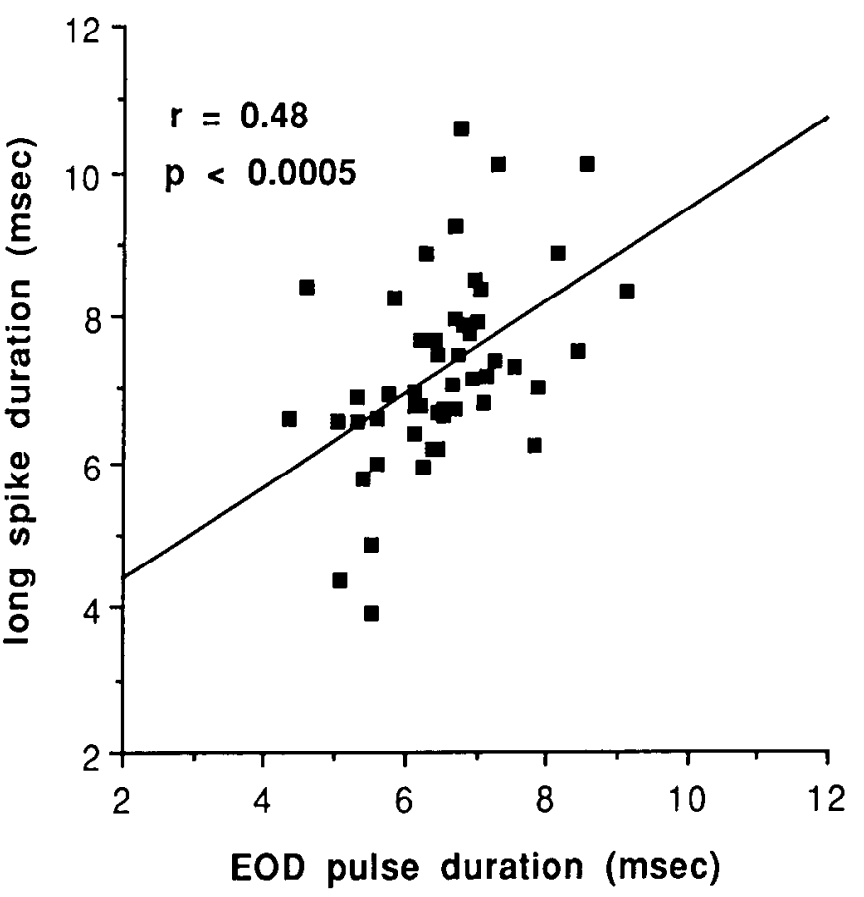

Figure 5. Long-spike duration is significantly correlated with EOD pulse duration. Regression line is shown

Short spikes. Minimum stimulus duration required to induce short APs ranged from 0.1 to $6.2 \mathrm{msec}$ (mean, $0.75 \pm 0.69$ $\mathrm{msec}$ ). Amplitudes ranged from 25 to $98 \mathrm{mV}$ (mean, $56 \pm 16$ $\mathrm{mV}$ ). In most cases, short-spike amplitude was very similar to the long-spike amplitude in a given cell.

As described in Materials and Methods, short APD was measured only from the peak of the AP to the end, because in the majority of the cases, the spike onset was obscured by the stimulus artifact. It is likely that the peak of the AP was also obscured in some cases, thus introducing error into these measurements. The short APs with minimal obscuring of the rise were more similar in shape to EOD pulses than were the long APs, in that the slope of the falling phase of the short AP was closer to that of the EOD pulse (Fig. 3). Also, there were rarely any humps in short APs (only three cells out of 235 had humps, and in all of these cases, the stimulus duration was longer than usual). In the few cases in which the short AP was not obscured by the stimulus pulse, the entire APD was shorter than that of the long AP in the same cell, hence the designation "long" and "short" spikcs. Mcan short APD ranged from 1.87 to $5.42 \mathrm{msec}$. The short APD was generally shorter than the long-AP falling phase duration in the same fish, though highly correlated $(r=0.64 ; p$ $<0.00005$ ). Short-AP fall duration ranged from $0.14 \mathrm{msec}$ longer to 2.83 msec shorter than long-AP fall duration (Fig. 6; mean difference, $1.35 \pm 1.07 \mathrm{msec}$ shorter than long-AP fall time; $p$ $<0.005)$.

Short-APD fall time was also usually shorter than EOD pulse fall time (Fig. 6); the difference ranged from 1.54 msec greater to $2.36 \mathrm{msec}$ shorter than EOD fall time (mean difference, 0.66 $\pm 0.76 \mathrm{msec}$ shorter than EOD fall time; $p<0.005$ ). However, the correlation of short-AP fall time to EOD-pulse falling-phase duration was not significant, nor was the correlation to EOD frequency. Thus, short spikes are not generally useful for determining correlations between electrocyte activity and EOD pulse.

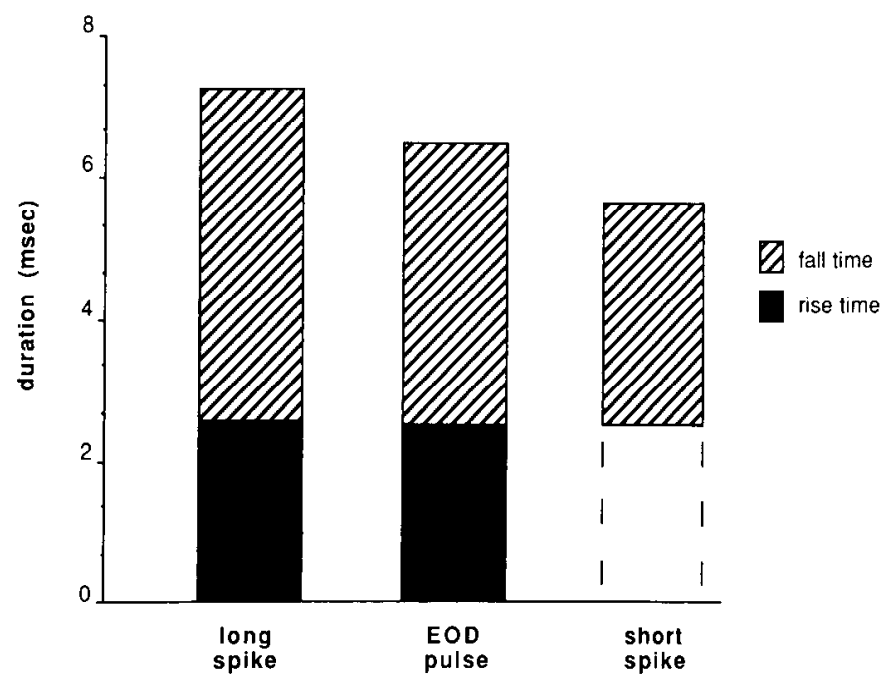

Figure 6. The mean duration of long spike, short spike, and EOD pulse in all fish. Rise time and fall time of long spikes and EOD pulses are differentiated by shading, only the fall time of short spikes was measured. Long spike (mean $\pm \mathrm{SE}$ ): rise time, $2.65 \pm 0.04 \mathrm{msec}$; fall time, $4.69 \pm 0.09 \mathrm{msec}$; total duration, $7.27 \pm 0.18 \mathrm{msec}$; EOD pulse: rise time, $2.53 \pm 0.07 \mathrm{msec}$; fall time, $3.97 \pm 0.08 \mathrm{msec}$; total duration, $6.5 \pm 0.14 \mathrm{msec}$; short spike: fall time, $3.33 \pm 0.10 \mathrm{msec}$. The fall times are all significantly different $(p<0.005)$.

Spontaneous spikes. A total of 36 cells from 24 fish spontaneously fired spikes upon penetration by electrodes. In all cases, $V_{m}$ in such a cell was depolarized relative to the normal $V_{m}$ of -69 $\mathrm{mV} ; V_{m}$ ranged from -60 to $-13 \mathrm{mV}$ (mean, $-34 \pm 13 \mathrm{mV}$ ). It is likely that this spontaneous activity was due to depolarization past threshold, as a result of damage to the cell membrane by the electrode. The spontaneous APs were fired at a regular rhythm unrelated to EOD frequency; spontaneous frequency ranged from 33 to $87 \mathrm{~Hz}$ (mean, $49 \pm 15 \mathrm{~Hz}$ ). The amplitude of spontaneous APs was lower than the amplitudes of induced APs. Spontaneous APD tended to be much broader than long APD and EOD pulse duration. There was no correlation between spontaneous APD or spontaneous frequency with EOD pulse duration, or with mean long APD, in a given fish.

\section{Effects of DHT on APS}

The EOD-frequency and pulse-duration ranges in the 22 fish prior to treatment were, respectively, 92-171 Hz and 4.33-7.09 msec in the DHT group and 98-148 Hz and 5.02-6.68 msec in the control group. Ten of the 14 DHT-treated fish responded with lowered EOD frequencies and increased pulse durations (the other four fish did not show any change in EOD frequency despite repeated implantation, and so were not included in the data analysis). The range of change was -19 to $-66 \mathrm{~Hz}$, with an average EOD frequency decline of $-34 \pm 5 \mathrm{~Hz}(\mathrm{SE})$. EOD pulse durations increased +0.36 to $+2.64 \mathrm{msec}$ (Fig. 7; see also Fig. 9), with an average of $+0.95 \perp 0.21 \mathrm{msec}$ (SE). Duty cycle in DHT fish decreased by an average of $-13 \pm 3 \%(\mathrm{SE})$. All of these changes in the DHT fish were statistically significant $(p<$ 0.005 , one-tailed). Control EODs showed no systematic change; frequencies changed by -8 to $+11 \mathrm{~Hz}$ (mean change, $-1 \pm 2$ $\mathrm{Hz}, \mathrm{SE}$ ), and pulse durations changed by -1.33 to $+0.48 \mathrm{msec}$ (Figs. 8, 9; mean change, $-0.19 \pm 0.21 \mathrm{msec}, \mathrm{SE}$ ). Duty cycle changed by an average of $-3 \pm 2 \%$ (SE). All of the changes in the control fish EODs were not statistically significant. The 


\section{DHT}

a

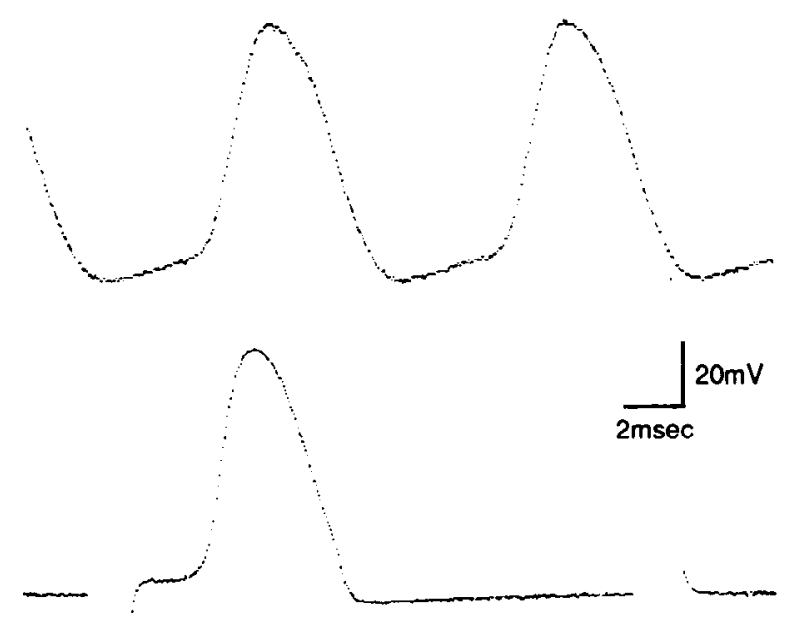

b after

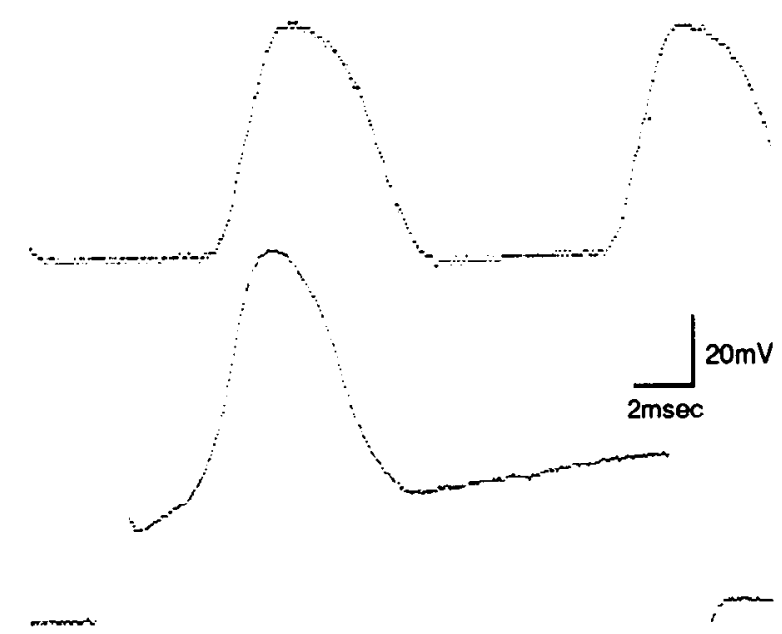

Figure 7. EOD (top traces) and long spike (bottom traces) in a DHT-treated fish, before $(a)$ and after $(b)$ treatment. Scale bars represent time in all traces, and amplitude only in the spike traces.

changes in the EODs of DHT-treated fish were also significantly different from the changes in the control fish $(p<0.001$, onetailed).

Rise time of the EOD pulse in the DHT group increased by an average of $0.37 \mathrm{msec}(p<0.005$, one-tailed), and fall time increased by an average of $0.58 \mathrm{msec}(p<0.01$, one-tailed). Percent rise and fall did not change. There were no significant changes in EOD pulse rise, fall, percent rise, or percent fall in control groups. The changes in EOD rise and fall times in the DHT group were also significantly different from those changes in the control group ( $p<0.05$, one-tailcd).

Changes in long spikes in most cases reflected changes in EOD pulse (Figs. 7, 9). Long APD increased in all but one fish in response to DHT; in this fish, the mean change in all cells recorded from was 0 . This fish showed a significant change in EOD frequency and pulse duration, however. The increase in long APD in the remaining DHT-treated fish $(N=9)$ ranged from +0.46 to $+3.62 \mathrm{msec}$ (mean change of all DHT fish, +1.48 $\pm 0.35 \mathrm{msec}, \mathrm{SE} ; p<0.005$, one-tailed; $N=10$ ). The long APDs in the control fish changed randomly, from -2.03 to $+0.82 \mathrm{msec}$ (Figs. 8, 9; mean, $-0.28 \pm 0.46 \mathrm{msec}$, SE). The changes in the APDs in the DHT-treated fish were also significantly different from the changes in APDs in the control group $(p<0.02$, one-tailed).

\section{CONTROL}

a
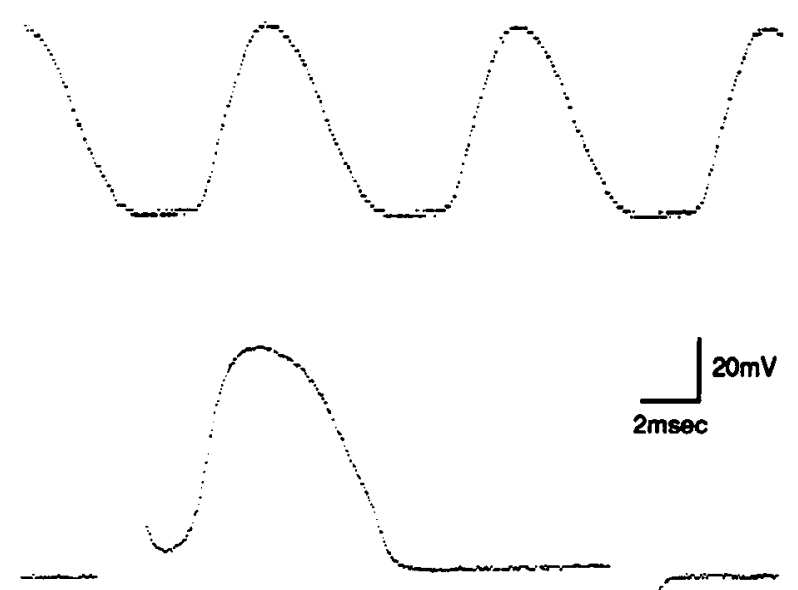

b

after
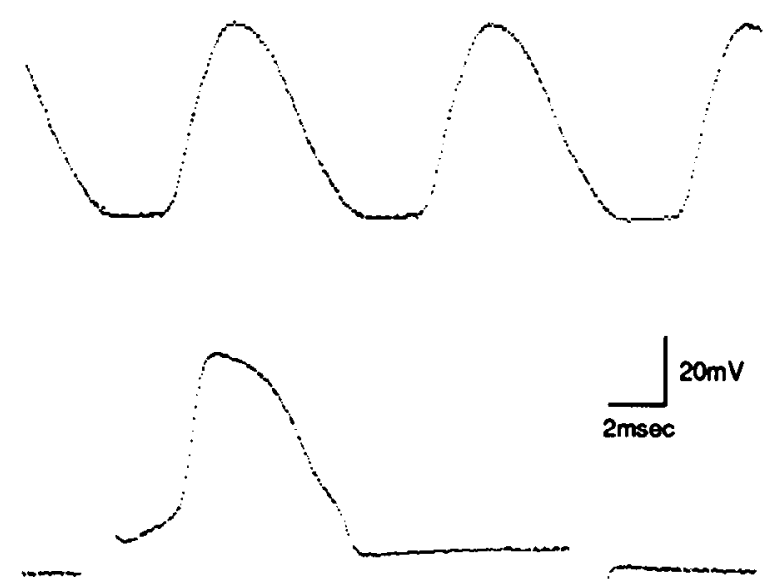

Figure 8. EOD (top traces) and long spike (bottom traces) in a control fish, before (a) and after (b) treatment. Scale bars represent time in all traces, and amplitude only in the spike traces. 


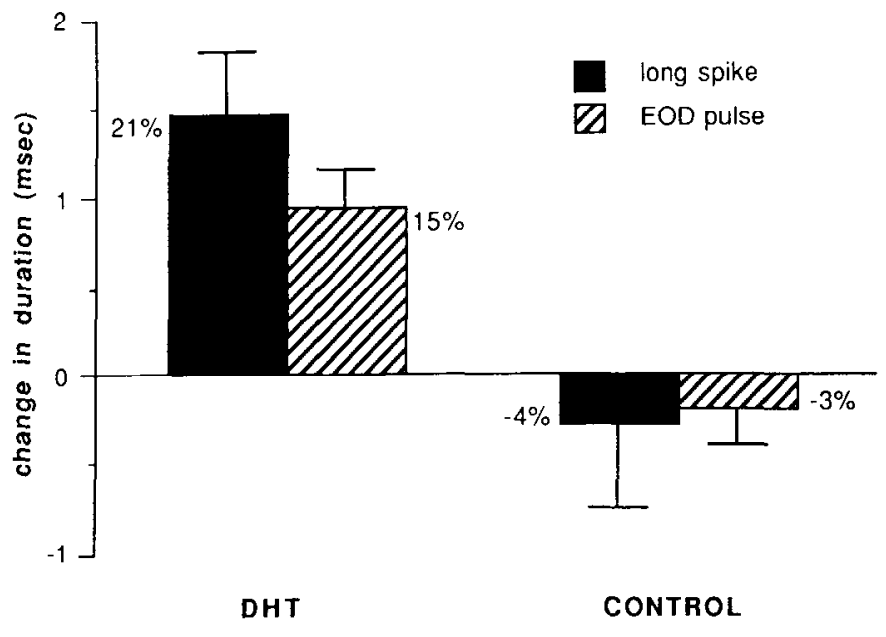

Figure 9. The mean change in duration of EOD pulse and long spike in all fish, with SE bars, in the DHT-treated and control fish. DHT: mean pulse duration increase, $0.95 \pm 0.21 \mathrm{msec}$; mean spike duration increase, $1.48 \pm 0.35 \mathrm{msec}$. Control: mean pulse change, $-0.19 \pm 0.21$ msec; mean spike change, $-0.28 \pm 0.46 \mathrm{msec}$.

The rise and fall times of the APs in the DHT-treated group increased significantly $(p<0.05$, one-tailed; mean rise time change, $+0.54 \pm 0.26$; mean fall time change, $+0.82 \pm 0.37$ $\mathrm{SE}$ ). The percent rise and percent fall times did not change significantly. The control group showed no changes in rise, fall, percent rise, or percent fall times. The increase in AP fall time in the DHT group was also significantly different from the variation of fall time in the control group ( $p<0.05$, one-tailed), but the increase in rise time was not different from the variation in rise time in the control fish. Electrocyte resting membrane potential and amplitude in all fish did not change in either group.

The short AP in a given fish did not necessarily reflect the same direction or relative magnitude of change as the long AP; because it was shown earlier that short APD is poorly correlated with EOD pulse duration, the short AP data for this portion of the study are not reported.

\section{Discussion}

There were two main findings in this study. First, single electrocyte spikes accurately reflect single EOD pulses; the mean APD of individual electrocytes recorded in a fish is significantly correlated with its EOD pulse duration. Second, mean APD increases significantly in fish treated with DHT, reflecting the DHT-induced increase in EOD pulse duration. Because the electromotor synapse did not participate in the experimentally induced APs, DHT must have acted either directly or indirectly upon the electric organ itself to cause this increase in APD.

\section{General characterization}

The EOD. Confirming the results of the previous study (Mills and Zakon, 1987), EOD pulse duration and EOD frequency are highly correlated: fish with lower EOD frequencies have longer pulse durations than fish with higher EOD frequencies. Duty cycle is also correlated with EOD frequency (fish with higher EOD frequencies have greater duty cycles), but not with EOD pulse duration. (This lack of correlation with EOD pulse duration may be due to the presence of more error in the pulseduration measurements, because judgment of where a pulse begins and ends is slightly subjective.)
Electrocyte AP properties. We have characterized some of the electrophysiological properties of Sternopygus electrocytes. Bennett (1971) qualitatively described APs in an earlier study, but did not include a systematic, quantitative comparison of AP properties with those of the corresponding EOD pulses.

We found that electrocyte APs resulting from 16-20-msec intracellular current pulses look very similar to the EOD pulse previously recorded from the same fish. On average, APs did not overshoot $0 \mathrm{mV}$, but half of the lower-threshold subset of cells did overshoot $0 \mathrm{mV}$ (mcan, $11 \pm 12 \mathrm{mV}$ ). However, they did not approach the typical equilibrium potential for sodium currents. Bennett (1961) recorded APs at the anterior and posterior ends of electrocytes with two intracellular electrodes, in the electric organ of an intact Sternopygus with an ongoing EOD. He showed that APs at the more posterior electrode were usually overshooting, while those recorded at the more anterior electrode usually did not overshoot $0 \mathrm{mV}$. Thus, an explanation for the lower average amplitudes reported here is that they were recorded at too great a distance from the active membrane, because we consistently recorded from an electrode placed anterior to the stimulating electrode. The subset of lower-threshold, higher-amplitude spikes probably represents electrocytes in which the electrodes were closer to the active membrane. The positive correlation between the magnitude of the $V_{m}$ and AP amplitude is a result of the slightly greater $V_{m}$ and higher AP amplitude measured at the postcrior end of the cell, relative to the measurements at the anterior end (the significance of the differential $V_{m}$ along the length of the electrocyte is explained in Bennett, 1961).

APDs were greater than EOD pulse durations, though they were significantly correlated; the correlation is lower than we reported in a previous abstract (Mills and Zakon, 1989), but is more meaningful due to the larger sample size. A significant correlation was expected, because the EOD pulse is made up of the summed spikes of the electrocytes as they are synchronously activated. AP rise time was the same as EOD pulse rise time, but the fall time of APs was longer than the fall time of EOD pulses. Thus, as explained below, events occurring during the falling phase of the spike are responsible for its longer duration compared to the EOD pulse.

The spontaneous APs, which are similar to the long APs in that depolarization (by cell damage rather than current injection) is maintained throughout the spike, also tended to be broader than EOD pulses, especially in the falling phase. Spontaneous APs were not significantly different in duration from regular long APs, but were greater in duration than short APs and EOD pulses. This suggests that maintained depolarization can contribute to increases in APD. As with long APs, the fall time of spontaneous APs was longer than that of the EOD pulse. Other sources of deviation are explained in the following sections.

Long-spike rising phase. One difference in shape between spikes and EOD pulses is the presence of an inflection in the rising phase of some low-frequency EOD pulses. These inflections represent the rise of the summed postsynaptic potentials (PSPs) of the electrocytes (Mills and Zakon, 1987) and form the subthreshold portion of the rising phase of the EOD pulse. Because the inflections were very slight in low-frequency EODs, and indistinguishable from the rest of the EOD pulse in high-frequency EODs, they were included in the measurement of EOD pulse duration. Electrocytes in this study were stimulated directly by injection of current, bypassing the synapse, so there was no PSP in the rising phase of the APs. Because EOD pulse 
rise time was not greater than AP rise time, including the compound PSPs in the EOD pulse measurement did not appreciably add to pulse duration.

Normally, the ACh-activated channels of the electrocyte are open prior to and during part of the rising phase of the AP. These open channels probably shunt some of the current of the rising phase of the $\mathrm{AP}$, presumably increasing its rise time, and thus that of the EOD pulse. It is surprising, then, that the rise times of the APs and EOD pulses were the same, because the electrocyte $\mathrm{ACh}$ channels are not activated with intracellular current injection. This shunting, if it occurs, must not significantly contribute to the rise time of the AP, because AP and EOD pulse rise times were identical.

Long-spike falling phase. Normally, as mentioned above, an electrocyte is induced to fire by a brief pulse of $\mathrm{ACh}$ released from the innervating electromotor neuron terminals. Thus, the depolarization induced by the neurotransmitter is short-lasting. Because of the large size of the electrocytes in Sternopygus, with a bricf stimulus pulse large amounts of current are needed to bring the cell to threshold. The resulting stimulus artifact usually obscures the rising portion of the spike (Bennett, 1971; present results). To circumvent this problem, we used a long-duration stimulus pulse that lasted throughout the AP. This maintained depolarizing current may have altered the properties of the falling phase of the AP. Not surprisingly, the total APD was affected; because rise time of the AP was the same as rise time of the EOD pulse, it appears that only the falling phase was influenced by the maintained depolarizing current. That the broadening is a consequence of the long-duration stimulus pulse is supported by the lack of broadening in the falling phase of both "rebound" spikes (not quantified because of small sample size), which fired after cessation of a hyperpolarizing stimulus, and short APs, which are induced by short-duration stimulus pulses.

The falling phase of long APs was longer relative to both the EOD pulse and the short APs (and sometimes the peak was broader in the long APs). The predominance of the falling phase suggests that potassium channels may be affected by the maintained depolarization, because potassium channels are normally responsible for repolarization of electrocytes (Bennett, 1971; Ferrari and Zakon, 1990). The longer falling phase of long APs compared to EOD pulses is also the reason the rise and fall times as percent of total duration differed betwecn APs and EOD pulses, because the absolute rise times were the same.

The presence in some long APs of a falling-phase hump, which was rarely seen in short APs and never in spontaneous APs or EOD pulses, suggests another reason for longer APDs. Even though an attempt was made to eliminate humps from the measurements, the adjusted values were still longer than APDs without humps in the same fish. Bourque and Renaud (1985) showed that the falling-phase hump in rat hypothalamic neurons was due to a calcium current. However, in Sternopygus, there is no calcium current during the electrocyte spike (Ferrari and Zakon, 1990). It is almost certain that the humps represent the reactivation (due to either the maintained depolarization itself, or unintentional indirect stimulation of innervating nerve terminals; Grundfest, 1957) of the conductances responsible for the rising phase of the AP (sodium conductances; Bennett, 1971; Ferrari and Zakon, 1990), as if the ccll were about to fire a second AP during the stimulus pulse. (In a few cases, a second, smaller AP was in fact recorded.) Such an activation could lengthen APD by canceling out some of the effect of the repolarizing conductances, thereby slowing the repolarization; this is reflected in the longer falling-phase duration of long APs compared to short APs and EOD pulse fall times. The lack of humps in most short APs, induced with short-duration stimuli, further corroborates the conclusion that humps result from the long duration of the stimulus pulse.

The shape of the APs with humps or secondary APs is very similar to the shape of an ongoing EOD, with a stimulus to the spinal cord added at various times relative to the firing of a pulse (Bennett, 1971). In those experiments, the second summed AP is induced cither during the interval between pulses, and is shorter in amplitude, or during the falling phase of an EOD pulse, adding to the falling phase as a hump. This further supports our argument that the hump in the falling phase of an AP merely represents the aborted firing of a second spike.

Comparison with other studies. The APs we recorded in Sternopygus look very similar to APs in other monophasically discharging gymnotiform species, though they are much broader in duration. For example, Electrophorus (electric eel) produces a 2-4-msec AP, monophasic Hypopomus species and Gymnotus produce a 1-2-msec AP, and Malapterurus generates an AP <1 msec in duration, all with a faster rise than fall (Bennett, 1971; Macadar et al., 1989), as is typical of most APs. Keynes and Martins-Ferreira (1953) and Grundfest (1957) recorded Electrophorus APs with falling-phase humps. The former investigators showed that a hump was more likely to be recorded near the active membranc, indicating that the hump represented a PSP, fired in response to unintentional stimulation of the innervating neuron terminals.

AP amplitudes in Electrophorus electrocytes (from both the "social" Sachs electric organ and the "offensive/defensive" main electric organ) are greater than those of Sternopygus, in spite of their shorter duration (amplitude, $\sim 150 \mathrm{mV}$; Keynes and Martins-Ferreira, 1953). In the electric eel, the AP approaches the equilibrium potential for sodium, due to the occurrence of potassium inactivation and a lack of outward current to quickly repolarize the cell. In Sternopygus, on the other hand, AP amplitude never approaches the sodium equilibrium potential, due to large outward currents (Ferrari and Zakon, 1990). This is important because the electric eel uses its EOD for defense and offense as well as for orientation and so must generate a largeamplitude electric field in order to deter or stun predators or prey. There is no known requirement for a large-amplitude EOD for communication; thus, Sternopygus may not have a need to generate a high-intensity EOD.

\section{The effects of DHT on electrocyte APS}

Treatment with the androgen DHT resulted in a lowering of EOD frequency and increase in EOD pulse duration, as previously reported (Mills and Zakon, 1987). The effects on the EOD are similar in magnitude to this study except that pulse durations in the DHT-treated group did not show as strong a response in this study [mean increase of $+0.92 \mathrm{msec}(N=9)$ versus +1.30 msec $(N=6)$ in previous study].

Fish treated with DHT had longer APDs following treatment than before treatment, and control fish showed no change in APD. The change in APD in response to DHT treatment was greater than the change in EOD pulse duration ( $21 \%$ vs. $15 \%)$. This reflects the general trend of $\Lambda$ PDs to be longer than the EOD pulse durations, especially in fish of lower EOD frequency, and is probably due to effects of the maintained stimulus pulse during the recording of the APs. The one DHT-treated fish that did not show an increase in APD was unusual in that the mean 
APD of the electrocytes after treatment was lower than the mean EOD pulse duration. Because the EOD pulse of this fish did significantly increase, our explanation is that the mean APD was biased by unintentional nonrandom sampling of the tissue.

As expected, because rise and fall times are longer in normal fish with longer-duration EOD pulses, both the rise and fall time components of the AP increased significantly in response to DHT treatment. However, only the increase in fall time was significantly different from the random changes in the control group. The $p$ value calculated for comparing change in rise time between the two treatment groups was very close to 0.05 ; thus, it was close to an acceptable significance level. It is likely that, with a larger sample size, we would have seen significance in this measure. The rise and fall times measured as percent of total AP duration did not change; thus, the relative AP shape did not change.

Although we did not directly test the possibility that DHT alters the timing of firing of single electrocytes, other studies suggest that this would play a minor role. Bastian (1977) showed that the externally recorded EOD wave shape changes with recording electrode position relative to the fish, in a species in which electrocytes are not synchronously activated. We showed previously that EOD wave shape in Sternopygus does not change with electrode position around the fish (Mills and Zakon, 1987). Also, the summed PSPs of the electrocytes, recorded outside a lightly curarized fish, do not differ in duration among fish of widely different EOD pulse durations and frequencies (Mills and Zakon, 1987); this suggests a lack of systematic variation of this $\mathrm{ACh}$-dependent synaptic property. It therefore appears that an increase in the APD of single electrocytes is sufficient to account for the DHT-induced increase in EOD pulse duration.

The increase in APD with DHT treatment is similar to that rcportcd in pulsc fish. Bass and Volman (1987) reported a twoto threefold increase in APD in the pulse fish Brienomyrus. Although the increase reported in this study was on the order of $20 \%$ and Bass and Volman showed a $100-200 \%$ increase, the absolute change in milliseconds was greater in our study $(1.48$ vs. $0.25 \mathrm{msec}$ ). This difference in absolute magnitude of androgen-induced APD increase merely reflects the much shorter spike durations in Brienomyrus.

\section{Site of action of DHT}

DHT could broaden the EOD pulse by three potential mechanisms. First, if spike wave shape is immediately dependent upon the frequency at which the cell is driven, then the effect of DHT of lowering the firing frequency of the PMN might result in spike broadening. Such a phenomenon is observed in various excitable cells. In Aplysia pleural sensory neurons (Edstrom and Lukowiak, 1985) and rat supraoptic neurons (Bourque and Renaud, 1985), increasing stimulus frequency approximately 40fold results in an APD increase of 100-125\%. In both cases, the frequency-dependent increase in APD is blocked in the presence of calcium channel blockers or EGTA, indicating its reliance upon a calcium current. Either an increase or a decrease in APD occurs in rabbit heart ventricle cells with increasing stimulus frequency, depending upon the frequency range; both calcium and potassium channel blockers alter the change in APD (RuizPetrich and LeBlanc, 1989).

In Sternopygus, as shown in the previous study (Mills and Zakon, 1987), though EOD pulse duration is highly correlated with EOD frequency, it is not determined on a moment-to- moment basis by the PMN. This was demonstrated by lowering the EOD frequency with the anesthetic MS-222, which did not alter EOD pulse duration. The EOD pulse duration remained constant for up to 5-10 min over thousands of EOD cycles, despite the steadily decreasing EOD frequency. Also, there was no difference in electrocyte APD at $1 \mathrm{~Hz}$ compared to $3 \mathrm{~Hz}$, though this is not a large range of stimulus frequencies. Furthermore, because we did not elicit APs by stimulation at a rate equal to each fish's own EOD frequency, but still found a significant correlation between APD and EOD pulse duration, it is unlikely that stimulation frequency determines electrocyte APD.

Second, rather than spike broadening occurring as an immediate consequences of stimulus frequency, it could be due to long-term effects of a changed pacemaker firing frequency upon the electric organ. This possibility could be tested by lesioning the pacemaker of fish after initial clectrocytc recording, then recording from electrocytes again after several weeks of DHT treatment. If PMN firing frequency does not determine APD, APD should be increased in silenced fish. We have not, therefore, ruled out the possibility that steroid effects upon any part of the EOD-producing circuit may in turn induce some longterm change in the properties of the electric organ.

Last, the hormone could exert a direct effect upon the electrocyte proper or other elements of EOD production, independent of its effects on the PMN. The site determining EOD differences between fish, and thus the site of DHT action, could include other brain nuclei, the relay cells from the PMN to the spinal cord, the electromotor neurons, the electromotor neuronelectrocyte synapse, or the electric organ itself. The electric organ has been shown to contain high-affinity androgen receptors in another electric fish species (Bass et al., 1986b); thus, the electric organ is a potential androgen target.

The activity of brain nuclei, relay cells, the electromotor neurons, and properties of the electromotor neuron-electrocyte synapse were not directly investigated here. One possible mechanism is that the synaptic action of $\mathrm{ACh}$ is prolonged by some action of DHT upon one or more of the presynaptic elements, during normal EOD production, because we showed that APD is broader with longer stimulus duration. However, it has been shown in both a mormyrid and a gymnotiform pulse-fish species that the activity of the electromotor neurons does not vary systematically with the EOD (Bass and Hopkins, 1983; Hagedorn and Carr, 1985). Furthermore, we showed that compound PSP duration does not change after DHT treatment (Mills and Zakon, 1987). Thus, the electromotor neurons are unlikely to contribute to the coordination of EOD frequency with electrocyte activity, or to the response to DHT. Any effects of androgen upon these elements alone would not explain the increases in APD that we measured, because these structures were bypassed by our direct-stimulus paradigm. This leaves the electric organ itself as the most likely target of the DHT effects.

Passive membrane properties. Time constant (resistance $\times$ capacitance), a measure of passive membrane properties, would be expected to vary between fish of different EOD pulse durations and APDs, if it contributed significantly to the differences in these parameters between individual fish. Although we did not measure time constant, Bennett (1961) reported that it is very short relative to APD in Sternopygus. Nakamura et al. (1965) report a time constant of $57-180 \mu \mathrm{sec}$ in the closely related species Electrophorus. A brief time constant means that the cell membrane charges very rapidly; thus, the passive mem- 
brane properties should not have a large effect upon the rate of rise or the duration of the spike.

In some species of pulse fish, the morpholugy of the electrocytes is correlated with the EOD pulse wave form, such that males or androgen-treated fish with male-typical EOD pulses have larger electrocytes and/or thicker cell membranes than normal females (Hagedorn and Carr, 1985; Bass, 1986a; Bass et al., 1986a; Freedman et al., 1989). This addition of membrane increases the total membrane capacitance, which can increase the time constant and thus the charging time of the cell membrane. This could significantly add to the duration of the relatively bricf APs fircd by the elcctrocytes in pulse fish. It thus appears that one effect of androgen on the electrocytes of pulse fish is to increase the amount of membrane, thereby increasing APD. Preliminary studies suggest that there is no systematic variation in amount of cell membrane of electrocytes in Sternopygus of varying EOD pulse durations, or with DHT treatment (Mills et al., 1988); thus, unlike pulse fish, there is no anatomical evidence that passive membrane properties vary systematically among individual Sternopygus.

\section{Proposed mechanism of DHT-induced changes in APD}

The most likely candidate for mediating differences in APD and EOD pulse duration between fish, and the putative site of androgen action, is the ion channel properties that are responsible for the production of the AP. Endogenous androgen may normally regulate these channels, to ensure that the activity of the electrocytes changes in accordance with the EOD frequency.

A variety of hormones have been shown to have rapid, shortterm electrophysiological effects in other systems. Such effects include changes in action potential duration and amplitude, changes in cell excitability, and/or changes in ion conductance in response to starfish egg maturation hormone $l$-methyladenine (Moody and Lansman, 1983), vasopressin (Molokonova and Tamarova, 1988), thyroid hormone (Felzen et al., 1989) and a thyroxine-like drug (Aomine, 1988a,b), glucocorticoids (Joels and de Kloet, 1989; Kerr et al., 1989), steroid metabolites (Puia et al., 1990), and estradiol (Teyler et al., 1980; Yovanof and Feng, 1983; Kesner et al., 1987; Loose et al., 1989). However, these are all short-term effects that can occur as quickly as 30 min after treatment. In the electric fish, the steroid-induced changes are produced gradually over a few weeks, though they are first detectable in the EOD after $1 \mathrm{~d}$. Electrophysiological changes in APD and/or ion conductance with a longer time course (days to weeks) are seen in response to chronic treatment with NGF and corticosteroids (Rudy et al., 1982; Chalazonitis et al., 1987; Garber et al., 1989), estrogen (Boyle et al., 1987; Kesner et al., 1987), and thyroid hormone (Binah et al., 1987; Felzen et al., 1989).

The lengthy time necessary for changes in EOD pulse to occur in Sternopygus is indicative of the mechanism of hormone action. Long-latency steroid effects are genomic in nature (McEwen, 1981; Pfaff and McEwen, 1983). One possible mechanism for steroid action on cell electrophysiology is the synthesis and insertion of new ion channels into electrocyte membranes. The induction of ion channel synthesis has been shown in other tissues for sodium and calcium channels, in response to NGF and dexamethasone (Rudy et al., 1982; Garber et al., 1989), and for potassium channels in response to estrogen (Boyle et al., 1987; Pragnell et al., 1990; the former investigators suggest that estradiol controls the concentration of mRNA encoding uterine potassium channels, or a potassium channel modulatory protein). These new channels could alter the APD if their kinetics or quantity differed from that of the previous channels (Levitan, 1985).

Alternatively, the synthesis of a kinase may be induced by the steroid, which affects the existing ion channels. Kaczmarek (1988) suggests that changes in the phosphorylation state of ion channels or regulating components may lead to the acute appearance of new types of active channels, and that unmasking of channels may be a mechanism employed by cells subject to prolonged changes in excitability, to regulate long-lasting changes in the behavior of the animal.

If modulation of spike duration involves synthesis and insertion of new channels, the effects can be expected to require days or weeks to be completed. The sodium channels of the electric eel electrocytes require $24 \mathrm{hr}$ to be synthesized and processed to their mature form (Thornhill and Levinson, 1987). The change in cell current would occur gradually, as the existing population of channels was turned over. Normal turnover of ion channels can be slow, remaining static in untreated cells for $3 \mathrm{~d}$ or more (O'Dowd, 1983), and up to $30 \mathrm{~d}$ or more in some cells (Balice-Gordon et al., 1990). Treating fish with RNA or protein inhibitors concurrent with androgen therapy would test the idea that steroid effects on electrocytes are protein dependent.

Sternopygus electrocyte spikes consist of a rising phase due to a sodium current, and a falling phase due to delayed and outward-rectifying potassium currents; there is no calcium component (Bennett, 1961; Ferrari and Zakon, 1990). Although any electrocyte ion channel could be the target of DHT, potassium channels may be the most likely targets. The tendency of the percent of APD that is required for repolarization (the percent fall) to increase with APD supports this contention. Boyle et al. (1987) have demonstrated that uterine potassium channels can be modified by sex steroids.

The steroid-induced increase in APD in Sternopygus electrocytes could be accomplished through alteration of potassium currents alone. Ruben and Thompson (1984) showed that preventing potassium inactivation shortens the APD in molluscan neurons; in electrocytes, steroids may act to increase the time of potassium channel inactivation, thereby increasing APD (Bennett and Grundfest, 1966; Levitan, 1985). Bennett (1961) and Bennett and Grundfest (1966) suggested that the function of potassium inactivation in gymnotiform electrocytes is to allow the spike to overshoot $0 \mathrm{mV}$, thus producing a higheramplitude spike and EOD (the spike would not otherwise overshoot $0 \mathrm{mV}$, because the sodium conductance is less than the total resting conductance). We propose that another possible function is to allow for broadening of the spike duration and thus EOD pulse duration, while maintaining similar percent rise and percent fall times. (This preservation of the relative ratio of the durations of the rising and falling phases of the EOD may be important in communication, because the EOD wave form itself apparently contains information; Gottschalk, 1981.) The exact target of DHT must be determined through studies of individual ion channels, because it may act upon more than one channel type.

For the EOD to function as a sexually dimorphic behavior, there must be constant coordination of central pacemaker cells and peripheral effectors. It is intriguing that steroid hormones, through their varying effects on different cell types, can coordinate the production of a communication behavior. The studies of steroid effects on electric organ physiology in weakly electric 
fish represent a clear demonstration of steroid-induced physiological changes translating directly into behavior.

\section{References}

Altamirano M, Coates CW, Grundfest H, Nachmansohn D (1953) Mechanisms of bioelectric activity in electric tissue. I. The response to indirect and direct stimulation of electroplaques of Electrophorus clectricus. J Gen Physiol 37:91-110.

Aomine M (1988a) Acute effects of amiodarone on action potentials of isolated canine Purkinje fibers: comparison with tetrodotoxin effects. Gen Pharmacol 19:601-607.

Aomine M (1988b) Inhibition by amiodarone of slow response action potentials and contraction in guinea pig ventricular muscle. Gen Pharmacol 19:621-623.

Arnold AP, Bottjer SW, Brenowitz EA, Nordeen EJ, Nordeen KW (1986) Sexual dimorphisms in the neural vocal control system in song birds: ontogeny and phylogeny. Brain Behav Evol 28:22-31.

Baillet-Derbin C (1978) Cytodifferentiation of the regenerating electrocyte in an electric fish. Biol Cellulaire 33:15-24.

Balice-Gordon RJ, Breedlove SM, Bernstein S, Lichtman JW (1990) Neuromuscular junctions shrink and expand as muscle fiber size is manipulated: in vivo observations in the androgen-sensitive bulbocavernosus muscle of mice. J Neurosci 10:2660-2671.

Bass AH (1986a) Species differences in electric organs of mormyrids: substrates for species-typical electric organ discharge waveforms. J Comp Neurol 244:313-330.

Bass AH (1986b) Steroid-sensitive neuroeffector pathways for sonic and electric communication in fish. Brain Behav Evol 28:7-21.

Bass AH, Hopkins CD (1983) Hormonal control of sexual differentiation: changes in electric organ discharge waveform. Science 220: 971-974

Bass AH, Hopkins CD (1985) Hormonal control of sex differences in the electric organ discharge (EOD) of mormyrid fishes. J Comp Physiol 156:587-604.

Bass AH, Volman SF (1987) From behavior to membranes: testostcronc-induced changes in action potential duration in electric organs. Proc Natl Acad Sci USA 84:9295-9298.

Bass AH, Denizot J-P, Marchaterre MA (1986a) Ultrastructural features and hormone-dependent sex differences of mormyrid electric organs. J Comp Neurol 254:511-528.

Bass AH, Segil N, Kelley DB (1986b) Androgen binding in the brain and electric organ of a mormyrid fish. J Comp Physiol 159:535-544.

Bastian J (1977) Variations in the frequency response of electroreceptors dependent on receptor location in weakly electric fish (Gymnotoidei) with a pulse discharge. J Comp Physiol 121:53-64.

Bennett MVL (1961) Modes of operation of electric organs. Ann NY Acad Sci 54:458-494.

Bennett MVL (1971) Electric organs. In: Fish physiology, Vol V (Hoar WS, Randall DJ, eds), pp 347-491. New York: Academic.

Bennett MVL, Grundfest H (1966) Analysis of depolarizing and hyperpolarizing inactivation responses in gymnotid electroplaques. $\mathrm{J}$ Gen Physiol 50:141-169.

Bennett MVL, Pappas GD, Gimenez M, Nakajima Y (1967) Physiology and ultrastructure of electrotonic junctions. IV. Medullary electromotor nuclei in gymnotid fish. J Neurophysiol 30:236-300.

Binah O, Rubinstein I, Gilat E (1987) Effects of thyroid hormone on the action potential and membrane currents of guinea pig ventricular myocytes. Eur J Physiol 409:214-216.

Bourque CW, Renaud LP (1985) Activity dependence of action potential duration in rat supraoptic neurosecretory neurones recorded in vitro. J Physiol (Lond) 363:429-439.

Boyle MB, Azhderian EM, MacLusky NJ, Naftolin F, Kaczmarek LK (1987) Xenopus oocytes injected with rat uterine RNA express very slowly activating potassium currents. Science 235:1221-1224.

Bullock TH (1982) Electroreception. Annu Rev Neurosci 5:1-22.

Chalazonitis A, Peterson ER, Crain SM (1987) Nerve growth factor regulates the action potential duration of mature sensory neurons. Proc Natl Acad Sci USA 84:289-293.

Chan A, Dudley CA, Moss RL (1985) Hormonal modulation of the responsiveness of midbrain central gray neurons to LH-RH. Neuroendocrinology 41:163-168.

Edstrom JP, Lukowiak KD (1985) Frequency-dependent action potential prolongation in Aplysia pleural sensory neurones. Neuroscience $16: 451-460$.
Ellis DB, Szabo T (1980) Identification of different cell types in the command (pacemaker) nucleus of several gymnotiform species by retrograde transport of horseradish peroxidase. Neuroscience 5:19171929.

Enger PS, Szabo T (1968) Effects of temperature on the discharge rates of the electric organ of some gymnotids. Comp Biochem Physiol 27: 625-627.

Felzen B, Sweed Y, Binah O (1989) Electrophysiological effects of thyroid hormones in guinea-pig ventricular muscle: time course and relationships to blood levels. J Mol Cell Cardiol 21:1151-1161.

Ferrari MB, Zakon HH (1990) Conductances contributing to the action potential waveform of electrocytes in Sternopygus. Soc Neurosci Abstr $16: 1326$.

Freedman EG, Olyarchuk J, Marchaterre MA, Bass AH (1989) A temporal analysis of testosterone-induced changes in electric organs and electric organ discharges of mormyrid fishes. J Neurobiol 20:619634.

Garber SS, Hoshi T, Aldrich RW (1989) Regulation of ionic currents in pheochromocytoma cells by nerve growth factor and dexamethasone. J Neurosci 9:3976-3987.

Gottschalk B (1981) Electrocommunication in gymnotid wave fish: significance of a temporal feature in the electric organ discharge. In: Sensory physiology of aquatic lower vertebrates, Vol 31 (S $\measuredangle$ abo T, Czeh G, eds), pp 225-278. New York: Pergamon.

Grundfest $H$ (1957) The mechanisms of discharge of the electric organs in relation to general and comparative electrophysiology. Progr Biophys Biophys Chem 7:3-85.

Hagedorn M, Carr C (1985) Single electrocytes produce a sexually dimorphic signal in South American electric fish, Hypopomus occidentalis (Gymnotiformes, Hypopomidae). J Comp Physiol 156:511523.

Hagedorn M, Heiligenberg W (1985) Court and spark: electric signals in the courtship and mating of gymnotid fish. Anim Behav 33:254 265.

Hopkins CD (1972) Sex differences in electric signaling in an electric fish. Science 176:1035-1037.

Ilopkins CD (1974) Electric communication in the reproductive behavior of Sternopygus macrurus (Gymnotoidei). Z Tierpsychol 35: 518-535.

Hopkins CD (1980) Evolution of electric communication channels of mormyrids. Behav Ecol Sociobiol 7:1-13.

Hopkins CD, Bass AH (1981) Temporal coding of species recognition signals in an electric fish. Science 212:85-87.

Joels M, de Kloet ER (1989) Effects of glucocorticoids and norepinephrine on the excitability in the hippocampus. Science $245: 1502$ 1504 .

Kaczmarek LK (1988) The regulation of neuronal calcium and potassium channels by protein phosphorylation. In: Advances in second messenger and phosphoprotein research, Vol 22 (Greengard P, Robison GA, eds), pp 113-138. New York: Raven.

Keller CH, Zakon HH, Sanchez DY (1986) Evidence for a direct effect of androgens upon electroreceptor tuning. J Comp Physiol 158:301310.

Kelley DB (1986) Neuroeffectors for vocalization in Xenopus laevis: hormonal regulations of sexual dimorphism. J Neurobiol 17:231248.

Kendrick KM, Drewett RF (1979) Testosterone reduces refractory period of stria terminalis neurons in the rat brain. Science 204:877879.

Kerr DS, Campbell LW, Hao S-Y, Landfield PW (1989) Corticosteroid modulation of hippocampal potentials: increased effect with aging. Science 245:1505-1509.

Kesner J, Wilson RC, Kaufman J-M, Hotchkiss J, Chen Y, Yamamoto H, Pardo RR, Knobil P (1987) Unexpected responses of the hypothalamic gonadotropin-releasing hormone "pulse generator" to physiological inputs in the absence of the ovary. Proc Natl Acad Sci USA 84:8745-8749.

Keynes RD, Martins-Ferreira H (1953) Membrane potentials in the electroplates of the electric eel. J Physiol (Lond) 119:315-351.

Landsman RE, Moller P (1988) Testosterone changes the electric organ discharge and external morphology of the mormyrid fish, Gnathonemus petersii (Mormyriformes). Experientia 44:900-903.

Levitan IB (1985) Phosphorylation of ion channels. J Membr Biol 87: $177-190$. 
Lissmann HW (1958) On the function and evolution of electric organs in fish. J Exp Biol 35:156-191.

Lissmann HW, Machin KE (1958) The mechanism of object location in Gymnarchus niloticus and similar fish. J Exp Biol 35:451-485.

Loose MD, Ronnekleiv OK, Kelly MJ (1989) Opioid action on arcuate (ARC) neurons: a voltage- and current-clamp study of unidentified and immunopositive $\beta$-endorphin and tyrosine hydroxylase neurons. Soc Neurosci Abstr 15:1087.

Macadar O, Lorenzo D, Velluti JC (1989) Waveform generation of the electric organ discharge in Gymnotus carapo. II. Electrophysiological properties of single electrocytes. J Comp Physiol 165:353-360.

McEwen BS (1981) Neural gonadal steroid actions. Science 211:13031311.

Meyer JH (1983) Steroid influences upon the discharge frequency of a weakly electric fish. J Comp Physiol 153:29-37.

Mills A, Zakon HH (1987) Coordination of EOD frequency and pulse duration in a weakly electric wave fish: the influence of androgens. $J$ Comp Physiol 161:417-430.

Mills A, Zakon HH (1989) Spike duration depends on stimulus duration in electric organ of Sternopygus. Soc Neurosci Abstr 15:1136.

Mills A, Zakon HH, Bass AH (1988) Physiological and anatomical correlates of the steroid-sensitive EOD of Sternopygus. Soc Neurosci Abstr 14:205.

Moller P, Serrier J (1986) Species recognition in mormyrid weakly electric fish. Anim Behav 34:333-339.

Molokonova EA, Tamarova ZA (1988) Effect of vasopressin on the somatic membrane of spinal ganglion neurons. Neirofiziologiia 20 : 801-808.

Moody WJ, Lansman JB (1983) Developmental regulation of $\mathrm{Ca}$ and $\mathrm{K}$ currents during hormone-induced maturation of starfish oocytes. Proc Natl Acad Sci USA 80:3096-3100.

Nakamura Y, Nakajima S, Grundfest H (1965) Analysis of spike electrogenesis and depolarizing $\mathrm{K}$ inactivation in electroplaques of Electrophorus electricus, L. J Gen Physiol 49:321-349.

O'Dowd DK (1983) RNA synthesis dependence of action potential development in spinal cord neurons. Nature 303:619-621.

Pfaff DW, McEwen BS (1983) Action of estrogens and progestins on nerve cells. Science 219:808-814.

Pragnell M, Snay KJ, Trimmer JS, MacLusky NJ, Naftolin E, Kaczmar- ek LK, Boyle MB (1990) Estrogen induction of a small putative K channel mRNA in rat uterus. Neuron 4:807-812.

Puia G, Santi M, Vicini S, Pritchett DB, Purdy RH, Paul SM, Seeburg PH, Costa E (1990) Neurosteroids act on recombinant human GABA receptors. Neuron 4:759-765.

Ruben P, Thompson S (1984) Rapid recovery from K current inactivation on membrane hyperpolarization in molluscan neurons. J Gen Physiol 84:861-875.

Rudy B, Kirschenbaum B, Greene LA (1982) Nerve growth factorinduced increase in saxitoxin binding to rat $\mathrm{PC} 12$ pheochromocytoma cells. J Neurosci 2:1405-1411.

Ruiz-Petrich E, LeBlanc N (1989) The mechanisms of the rate-dependent changes of the conducted action potential in rabbit ventricle. Can J Physiol Pharmacol 67:780-787.

Schwartz IR, Pappas GD, Bennett MVL (1975) The fine structure of electrocytes in weakly electric teleosts. J Neurocytol 4:87-114.

Sengelaub DR (1989) Cell generation, migration, death, and growth in neural systems mediating social behavior. In: Advances in comparative and environmental physiology, Vol 3 (Balthazart J, ed), pp 239-267. Berlin: Springer.

Teyler TJ, Lewis D, Rawitch AB (1980) Gonadal steroids: effects on excitability of hippocampal pyramidal cells. Science 209:1017-1019.

Thornhill WB, Levinson SR (1987) Biosynthesis of electroplax sodium channels in Electrophorus electrocytes and Xenopus oocytes. Biochemistry $26: 4381-4388$.

Westby GWM, Kirschbaum F (1981) Sex differences in the electric organ discharge of Eigenmannia virescens and the effects of gonadal maturation. In: Sensory physiology of aquatic lower vertebrates (Szabo T, Czeh G, eds), pp 179-194. New York: Pergamon.

Westby GWM, Kirschbaum F (1982) Sex differences in the waveform of the pulse-type electric fish, Pollimyrus isidori (Mormyridae). J Comp Physiol 145:399-403.

Yovanof S, Feng AS (1983) Effects of estradiol on auditory evoked responses from the frog's auditory midbrain. Neurosci Lett 36:291297.

Zakon HH, Meyer JH (1983) Plasticity of electroreceptor tuning in the weakly electric fish, Sternopygus dariensis. J Comp Physiol 153: $477-487$. 